\title{
Proposições para uma Pedagogia Radical, ou Como Repensar Valores
}

\section{Erin Manning}

Tradução Bianca Scliar

Texto originalmente publicado em www.inflexions.org. Vol:8 Radical Pedagogies. Original disponível em http://www.inflexions.org/radicalpedagogy/main.html\#Manning 


\section{ESTUDO}

$\mathrm{P}$ ermita que as classes sejam um convite ao estudo, não um local de consumo de conhecimento. Esteja atento, pois algumas questões devem ser cobertas! O estudo, segundo argumentam Fred Moten e Stefano Harney, deve ser pautado pela criação de dissonâncias. Trata-se de permitir que a aprendizagem continue, ao invés de continuamente cortarmos a aprendizagem em nome do que decidimos, antecipadamente, antes do encontro. Não olhe tão duramente para a teia que é apenas uma passagem. Não se preocupe demais em desenhar uma linha, faça do aprendizado uma onda.

\section{COMECE Do Meio}

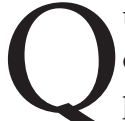

uando fazemos do estudo um modo de entrar no pacto de aprendizagem, precisamos desaprender o hábito de parar o pensamento para que o re-iniciemos. Pense em todas as vezes quando você entrou em uma sala de aula onde havia uma discussão calorosa que cessou com a entrada do professor. Nós, professores, tendemos a posicionar as classes desta forma, marcando nossa entrada como se ali fosse o princípio da aprendizagem. O que fica perdido neste gesto? O que permanece não ouvido?

"Recuse chamar a atenção da classe em nome de uma ordem", sugerem Moten e Harney. Reconheça a fragilidade da aprendizagem. Aprenda a ouvir desde o meio de tantas conversações. Conecte-se ao ritmo. Pense nelas como se fossem paisagem sonora:

Quando ouvimos música, precisamos recusar a ideia de que a música acontece apenas quando os músicos entram e tomam seus instrumentos em mãos; a música também está na antecipação da performance, nos ruídos da apreciação e também nas falas que acontecem sobre e em torno dela, tecendo-a amando-a, estando ali enquanto ouvimos (HALBERSTAM, in: Harney \& Moten 2013, p. 9, tradução da autora).

A paisagem sonora da aprendizagem está cheia de manchas de tinta que se alojam nos limites do que chamamos percepção. Pense no local da aprendizagem e delineie o que não pode exatamente ser articulado, ouça o que eles evocam, como soam, mesmo quando você quase não pode ouvi-lo. 
Quando recusamos manter a ordem - o professor tomando o livro, o condutor erguendo sua batuta, o conferencista pedindo silêncio, o torturador apertando o laço - recusamos a ordem enquanto distinção entre o que é ruído e o que é música, conversa e conhecimento, dor e verdade (HALBERSTAM, in: Harney \& Moten 2013, p. 9).

\section{Pense Além da Instituiç̃̃o}

U

$m$ processo pedagógico que principia pelo meio tem mais dificuldade de discernir quem faz o ensino e quem faz a aprendizagem. Quando esta distinção eclode, então a classe já começou. O pensamento visto como um pré-requisito pela instituição, não é aí o que está em jogo, embora provavelmente esteja sendo aprendido, de vez em quando. A instituição pode fornecer um sítio, mas o aprendizado não pode senão $o$ superar. Não há maneira de manter a aprendizagem presa ao currículo.

Valorize o que excede o currículo, o desconhecido como o que se ouve nos interstícios de uma paisagem Sonora não aprazível que é uma classe flutuante. Ouça aí, onde o valor está ainda em formação.

\section{Para Além do Valor}

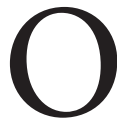

Valor na universidade é medido em créditos. Cada crédito equivale a uma tarifa. Para alguns, tais taxas são exorbitantes, levando ao círculo vicioso entre crédito e débito. Para outros, é financeiramente viável e assim preservamos a ideia de dívida. De qualquer modo, o débito está em jogo. Ele nos assombra, nos atravessa, e sustenta, como um presente recebido que é deixado de lado.

Existe uma relação direta entre os créditos e o valor da educação na instituição acadêmica credenciada. O quanto somos bem sucedidos depende de nossa acumulação de créditos. Esta acumulação torna clara como a aprendizagem é vivida e definida. Com a acumulação de créditos, vem uma chamada à ordem. Há um modo de aprender, um material a ser cumprido, tarefas a serem avaliadas. O valor é diretamente vinculado ao uso: parte da lição que aprendemos (se formos bem sucedidos) é que nosso valor coincide com nossa habilidade de sermos mantidos sob controle, em ordem.

A estudante sub-comum (undercommons) resiste a ser mantida em ordem. Mas ela não o faz na forma de crítica. Sua recusa é afirmativa. Ela está entusiasmada com aprender, sua ânsia a leva a outro lugar além 
daquela manutenção da ordem, ou apenas da ordenação de seus créditos. De fato, ao ser chamada a atenção, ela praticamente sequer registra a ordem, pois está mais ocupada com sua aprendizagem. Esta estudante é uma péssima credora: ela não permitirá que um crédito arruíne sua vida. Ela tem uma verdadeira dívida, mantendo vários subempregos e, ainda assim, ela se recusa a desistir. E raramente ela ouve a chamada em nome dos créditos.

A estudante tem um hábito, um mau hábito. Ela estuda. Ela estuda, mas não aprende. Caso ela aprendesse, seu progresso poderia ser medido, seriam estabelecidos alguns atributos, a ela seriam dados créditos. Mas a estudante permanece estudando, permanece planejando estudar, correndo para estudar, mantém um plano de estudos e se mantém na elaboração de seus créditos. A estudante não pretende pagar (HARNEY; MOTEN, 2013, p. 62).

Quem é esta estudante que (des)aprende, na dívida, para além dos créditos? Ela é a estudante que lê e fala e que sonha seus estudos. Ela é a estudante que você descobre tão logo você esteja pronto para, do mesmo modo que ela faz, resistir a render-se à ordem. Ela é aquela que assume uma posição e não discrimina entre as nuances e sombras da aprendizagem. A sala de aula é um dos únicos locais onde ela inventa e explora. Ela é a estudante que permanece além do interesse, em um campo de relações que não aceitam o círculo vicioso entre crédito e débito, que compreende previamente que a dívida sempre será maior do que a capacidade de ser recompensado, que sabe que a aprendizagem não pode ser encapsulada em um interesse demarcado previamente antes que algo seja dado. Ela pensa na aprendizagem como um presente.

Ela sabe que a dívida excede imensamente seus créditos e tem orgulho de ter dívidas para aprender. Ela compromete-se e honra seus débitos. Quanto mais ela aprende mais comprometida ela fica. Este é um aprendizado que recusa o crédito, que recusa o ciclo que finge que nossas bases podem ser cobertas antecipadamente.

Interesse e os estudantes! O estudante pode ser calculado por suas dívidas, pode calcular suas dívidas com seus interesses. Ela está de olho nos créditos, de olho em sua graduação, de olho em ser creditada, de ter investido em educação, uma cidadã (62). 
Ela simplesmente não está interessada no que os créditos prometem. Ela prefere a difícil reciprocidade da dívida impagável e de presentes que não poderão ser retribuídos. Ela só sabe que a dívida e o crédito não devem ser tão facilmente alinhados, que o alinhamento da dívida e do crédito desacreditam seu dom, seu presente.

Ela não quer quantificar o interesse. Ela vai solicitar o crédito, mas ela não vai trabalhar para ele. Ela vai trabalhar apesar de dizer o que merece ser dito ou de não aprender o que não deve ser aprendido. Ela vai resistir à ideia de que a aprendizagem pode ser capturada pelos interesses de uma disciplina. Ela vai resistir à disciplina.

"A estudante com créditos pode privatizar sua própria universidade, O estudante pode fundar uma ONG, convidar outros a se identificarem com seus interesses, sentá-los à sua mesa, juntar-se a conversa global, falar por si mesma, ter crédito, manejar seus débitos" (62)

Esta estudante não quer uma universidade privada, ela entende que isso apenas aumenta a necessidade por créditos. E ela também inventa outros tipos de coletividades, participando dos sub-comuns quando eles emergem.

\section{Além da Avaliaç̃̃o}

$\mathrm{E}$

la é difícil de ser avaliada, esta estudante que resiste aos créditos. A instituição a considera escorregadia: ela faz seu trabalho, consegue pontuações por isso, mas isso não parece motivá-la. Ela sabe como escrever bem, como cobrir as bases fundamentais, entretanto, quando permanece neste comportamento ela se sente adentrando um buraco negro. Há algo além em jogo e é isso que a motiva.

Como ensinar uma estudante como esta, que aprende além, que aprende apesar da avaliação? A estudante que tem presença forte e que segue seu próprio impulso? A estudante que não teme o atrito, que se adapta não apenas às questões propostas, mas que permanece pré-articulada, apesar de audível?

"O trabalho hoje é, a cada vez, associado a um fazer sem pensamento, sentir sem emoção, mover sem fricção, adaptar-se sem questionar, traduzir sem pausar, desejar sem qualquer propósito, conectar sem interromper" (HARNEY; MOTEN 2013, p. 87). 


\section{Pragmática da Inutilidade}

U

ma pedagogia engajada com a pragmática da inutilidade inventa seu valor durante a aprendizagem. Ela não decide previamente o que é útil. De fato, ela é cética a respeito da própria ideia de que deveríamos saber previamente aonde o aprendizado nos levará. Toda a conversa sobre o futuro, sobre empregos e conquista de segurança cheira a uma política de poder. Não é esta a chamada à ordem? Como poderíamos saber o que terá valor em um tempo ainda a ser inventado? Mesmo o capital não pretende saber isso.

Uma pragmática do inútil é dedicada à inutilidade, a práticas que ainda não foram definidas de acordo com o valor imposto externamente. Uma pragmática do inútil celebra o fato de que não sabemos aonde um pensamento pode nos levar. Ela se deleita com o estudo por causa do estudo em si.

Uma pragmática do inútil é pragmática no sentido de que está absolutamente envolvida com o que está no mundo, agora mesmo, e especulativa no sentido de que está aberta à transformação pela força potencializadora de aonde o estudo pode nos levar.

\section{Fazendo-Pensando}

valor é frequentemente alinhado àquilo que pode ser articulado. $\mathrm{E} o$ que fazer das forças que são sentidas, mas que permanecem inefáveis? Quais outros modos de expressar e desafiar a articulação? Quais paisagens sonoras nos mobilizam mais por sua ressaca do que por suas ondas? $\mathrm{O}$ conceito do Infrafino de Duchamp toca na ressaca inefável da experiência.

O infrafino não pode ser generalizado através das iterações daquilo em que se torna. Ele é exemplar. Duchamp escreve: "Apenas podemos dar exemplos do infrafino. (DE DUVE, 1991, p. 160). De suas anotações pessoais tomamos:

O calor de um assento (que acaba de ser deixado) é o infrafino (\#4); As portas de um metrô - as pessoas que atravessam no último segundo/infrafino -- (9 recto); calças de veludo - /seu som sussurrante (na caminhada) produzido pelas duas pernas é um sinal da separação infrafina através do som (e não um som infrafino) (\#9 verso); A diferença entre o contato/ da água e do chumbo derretido por exemplo, ou do creme contra as paredes de seu próprio recipiente, movido em torno do líquido... esta diferença entre dois contatos é o infrafino (\#14). (PERLOFF, 2002, p. 101) 
O infrafino destaca o interesse no que está por trás da experiência, e ainda assim faz a diferença. Usualmente, o que pode ser efetivamente apreendido - a partilha real (actual) da experiência sendo feita - é sua medida de valor. O que não é efetivamente incluído na ocasião da experiência e, no evento, é considerado desnecessário. Esta porção não efetiva é não apenas difícil de ser descrita, mas imensurável. Como ela pode ser avaliada?

Entretanto é esta exata imensurabilidade que dá valor à experiência. A estudante sabe disso, e é por esta razão que ela aprende em todo o lugar a que vai. De fato, a universidade é apenas um dos muitos lugares onde ela experiencia a força profunda do subcomum. Às vezes ela até mesmo se pergunta se o incomum não tem uma reverberação mais preciosa longe das paredes da instituição acadêmica. Mas ela persiste porque é uma aprendiz-de-vida-inteira e ama a ideia de estar em um lugar dedicado à pedagogia. Ela sabe, por sua experiência valorizando as margens na experiência, que existem coletivos emergentes até mesmo nos mais rígidos dos sistemas. $\mathrm{E}$ então ela encontra modos de continuar a encontrar a divisa especulativa da experiência, explorando como ela colore o evento em seu pragmatismo. Como todos os aprendizes-de-vida-inteira, ela sabe da mágica das margens.

\section{Novas formas de CONHECIMENTO}

s margens são uma nova forma de conhecimento que esteve aqui
o tempo todo. A única razão pela qual não se destacaram é porque
ativam um tipo de valor que resiste à avaliação. Nós simplesmente não as conseguíamos ver, pois estávamos muito ocupados com avaliações. Isso pode ser vantajoso: elas ainda têm o potencial para criar novas formas de valor, novos modos inúteis de valorizar a experiência no fazer.

Se olharmos do ponto de vista de nossas avaliações, poderemos percebê-las: o pensamento sempre foi transversal, a sala de aula sempre foi um local para o aprendizado nas margens. O que precisamos não é uma nova sala de aula, nem novos estudantes, mas novas técnicas para orientar a percepção: pensar que estudar transversalmente envolve um repensar o conceito do pensamento em si mesmo. O pensamento é reorientado em direção a incipiência do evento ao nosso alcance, em direção ao questionamento do estudo, evitando limitá-lo às definições acadêmicas existentes da intelectualidade. Onde mais o pensamento acontece?

Também precisamos desacoplar o pensamento de sua dependência a um sujeito humano. O pensamento não ocorre primeiro na mente. Ele 
é incorporado. E a incorporação é sempre uma ecologia de práticas. Na ecologia de práticas não é a mente que fala, o que emerge não é uma narrativa centrada no sujeito, mas um reconto da mobilidade do pensamento, como ele se move e como o pensar move o mundo. Uma prática de aprendizagem coletiva trata de um movimento de pensamento, trata de engajar o pensar no limite imanente onde ele ainda está presente no ato.

A aprendizagem acontece através de nós, conosco. Somos portadores do pensamento no sentido de que ele é levado adiante. Nós nos movemos neste transporte, e este transporte nos move.

\section{Além do MÉTOdo}

$\mathrm{U}$

ma abordagem metodológica começa a desvendar se ela pergunta o que o conhecimento faz. O que o conhecimento faz não pode ser empacotado. Não há nenhuma chamada à ordem para o pensamento no ato. $\mathrm{O}$ estudo se infiltra, vaza, muda, salta.

Enquanto estudo, o que o pensamento pode fazer é começar a atender aos apetites ativados no cotidiano, levando o pensar-em-ação rigorosamente em seus próprios termos especulativos. O pensamento agora começa a coincidir com a definição mais criativa da filosofia, a filosofia que pergunta como e o que mais? Nenhum método ajudará a filosofia nesta empreitada de pensar no ato, nem qualquer método será um manto adequado para a dissonância da paisagem sonora do pensamento.

Cada pensamento no ato deve inventar suas próprias práticas para aprender, suas próprias técnicas para carregar. No estudo, o que buscamos não é a homogeneização do pensar-fazer mas a criação de condições para encontrar a transversalidade operativa da diferença no cerne da vida.

\section{Pesquisa-Criacĩo}

$\mathrm{N}$ o SenseLab chamamos essa atividade de pensar-fazer de pesquisa-criação. Pesquisa-criação, como nós experimentamos, é estudo. Perguntamos: Como repensar sobre a forma como o conhecimento é criado no contexto de a prática artística tornar-se uma abertura para pensar a filosofia como uma prática? Como pode, seguindo Gilles Deleuze, o re-situar da pesquisa-criação, enquanto prática que pensa, nos fornecer um vocabulário para considerar seriamente que "a teoria filosófica é em si mesma uma prática, tanto quanto seu objeto"? 
"Não é mais abstrata do que seu objeto. É uma prática de conceitos e devemos julgá-la à luz das outras práticas com as quais interage “(DELEUZE, 1989, p. 280).

O que a pesquisa-criação faz é pedir-nos o envolvimento direto com um processo que, em muitos casos, não será ou não pode ser articulado na linguagem. Este é o paradoxo: que a filosofia quer sim encontrar palavras para o pensamento no ato. O trabalho contínuo que é a colaboração criativa que constitui a pesquisa-criação envolve honrar a dissonância do empurra-e-puxa das texturas e movimentos de prática que recusam ser nomeadas, sentindo as reverberações daquilo que não pode ser colocado em palavras, ao ativar na escrita, o infrafino que ressoa em tudo o que pode ser dito.

A pesquisa-criação não precisa de novos métodos. O que ela precisa é um re-conto do que a escrita pode fazer no processo de pensar-fazer. Isso envolve a experimentação com a escrita na margem, uma prática que se envolve com o ainda-não no cerne da aprendizagem. Isto é uma pedagogia radical: o compromisso com a criação de práticas que privilegiam o modo como a aprendizagem cria seu próprio valor. 


\section{REFERÊNCIAS}

DE DUVE, Thierry. The Definitely Unfinished Marcel Duchamp. Cambridge, Mass.: MIT Press, 1991.

DELEUZE, Gilles. Cinema 2: The Time-Image. Trad. Hugh Tomlinson and Robert Galeta. Minneapolis: University of Minnesota Press, 1989.

HARNEY, Stefano; MOTEN, Fred. The Undercommons: Fugitive Planning \& Black Study. Wivenhoe/New York/Port Watson: Minor Compositions, 2013.

PERLOFF, Marjorie. 21st-Century Modernism: The "New" Poetics. Oxford: Wiley- Blackwell, 2002. 